\title{
Metastases but not cardiovascular mortality reduces life expectancy following surgical resection of apparently benign pheochromocytoma
}

\author{
H J L M Timmers ${ }^{1 *}, F M$ Brouwers $^{2 *}$ A R M M Hermus ${ }^{1}, F C G J$ Sweep $^{3}$, \\ A A J Verhofstad ${ }^{4}, A L M$ Verbeek $^{5}, K$ Pacak $^{6}$ and J W M Lenders ${ }^{2}$ \\ Departments of ${ }^{1}$ Endocrinology (741), ${ }^{2}$ General Internal Medicine ${ }^{3}$ Chemical Endocrinology ${ }^{4}$ Pathology, Epidemiology and \\ ${ }^{5}$ Biostatistics, Radboud University Nijmegen Medical Centre, PO Box 9101, 6500 HB Nijmegen, The Netherlands \\ ${ }^{6}$ Department of Reproductive and Adult Endocrinology Program, National Institutes of Child Health and Human Development, \\ National Institutes of Health, Bethesda, Maryland, USA \\ (Correspondence should be addressed to H J L M Timmers; Email: h.timmers@endo.umcn.nl) \\ *(H J L M Timmers and F M Brouwers contributed equally to this work)
}

\begin{abstract}
The treatment of choice for non-metastatic pheochromocytoma is surgical resection. Its goals are to abolish catecholamine hypersecretion, normalize blood pressure, and prevent further tumor growth or progression to metastatic disease. Data on long-term mortality and morbidity after pheochromocytoma surgery are limited. We here report a retrospective study on the long-term outcome after surgery for apparently benign pheochromocytoma at the Radboud University Nijmegen Medical Centre. Data on clinical presentation, treatment, post-surgical blood pressure and recurrence, metastasis and death were collected of 69 consecutive patients (January 1966-December 2000; follow-up: until death or January 2006). Survival was compared with survival of a matched reference population. Two patients died of surgical complications. All ten patients with metastatic disease (including three diagnosed at first surgery) died. At follow-up, 40 patients were alive and recurrence free and three patients were lost to follow up. Two patients experienced a benign recurrence. Mean \pm S.D. follow-up was 10.2 \pm 7.5 (median 9, range 1-38) years. Kaplan-Meier estimates for 5- and 10-year survival since surgery were $85.8 \%(95 \% \mathrm{Cl}$ : $77.2-94.4 \%)$ and $74.2 \%(95 \% \mathrm{Cl}: 62.0-86.4 \%)$ for patients versus 95.5 and $89.4 \%$ in the reference population $(P<0.05)$. Sixty-four percent of all patients with hypertension prior to surgery showed a significant decrease in blood pressure, but remained hypertensive after surgery. In conclusion, compared with the general population patients have a reduced life expectancy following pheochromocytoma surgery, due to their risk of developing metastatic disease. Only one-third becomes normotensive without antihypertensive medication. Therefore, lifelong follow-up is warranted.
\end{abstract}

Endocrine-Related Cancer (2008) 15 1127-1133

\section{Introduction}

Pheochromocytoma (PHEO) is a rare catecholamine producing tumor that derives from chromaffin cells of the adrenal medulla or extra-adrenal abdominal and thoracic paraganglia (DeLellis et al. 2004, Lenders et al. 2005, Pacak et al. 2005). Symptoms, signs and complications of PHEO are mainly related to hypersecretion of catecholamines. These include headache, palpitations, diaphoresis, and hypertension. Once the biochemical diagnosis of PHEO is established by plasma and/or urine measurements of catecholamines and their metabolites (Lenders et al. 2002), tumors are localized by anatomical or functional imaging, such as ${ }^{123}$ I-MIBG scintigraphy (Ilias et al. 2005). 
Treatment of non-metastatic PHEO consists of surgical resection following preoperative pharmacological sympathetic blockade (van der Horst-Schrivers et al. 2006). The aims of surgery are abolishment of catecholamine hypersecretion, normalization of blood pressure, and prevention of further tumor growth and progression to metastatic disease. The long-term outcome of patients after PHEO surgery has been addressed in a limited number of studies. Estimates of benign and malignant recurrence rate after surgery vary between 6 and 23\% (Modlin et al. 1979, Scott \& Halter 1984, van Heerden et al. 1990, Pruszczyk et al. 1991, Plouin et al. 1997). Conflicting results of previous cohort studies suggest that the life expectancy after PHEO surgery is either normal (Stenstrom et al. 1988) or decreased (Khorram-Manesh et al. 2005) when compared with the general population. Furthermore, though PHEO is generally considered to be a surgically curable cause of secondary hypertension, blood pressure remains elevated after surgery in a considerable number of patients without recurrent disease (Plouin et al. 1997, Khorram-Manesh et al. 2005).

The aim of this study was to investigate the longterm follow-up of patients after surgery for apparently benign PHEO. Survival was compared with results obtained from a period-, age-, and gender-matched Dutch reference population.

\section{Methods}

\section{Patients}

To evaluate long-term outcome, the study was restricted to patients diagnosed with PHEO before January 2001. From January 1966 until December 2000, 71 patients with a histologically confirmed diagnosis of PHEO were evaluated at the departments of General Internal Medicine and Endocrinology at the Radboud University Nijmegen Medical Centre. In all but four patients, initial PHEO surgery was performed at our centre. Two patients were excluded from the study: one patient was referred to our center because of metastases and in a female patient who died during Caesarian section the PHEO was found at autopsy. This left 69 patients (44 females, 25 males) for evaluation of follow-up after surgery for apparently benign PHEO.

\section{Initial work up, surgery, and follow-up}

For the biochemical diagnosis of PHEO, plasma and 24-h urine were assayed by HPLC for concentrations of catecholamines (plasma $n=59$, urine $n=38$ ) and urine fractionated metanephrines $(n=12)$, according to previously described procedures (Willemsen et al. 1995, 2003). CT $(n=57)$, MRI $(n=4)$, abdominal ultrasound $(n=36)$ and ${ }^{123}$ I-MIBG scintigraphy $(n=42)$ were employed to localize the tumor(s). Except for three laparoscopic adrenalectomies, tumors were resected by open procedures (including four that initially started laparoscopically). Five patients with bilateral tumors underwent staged open surgery. Surgery was performed before 1990 in 43 per cent (29 out of the 68) of patients. Plasma and urine concentrations of catecholamines and metanephrines were reassessed after a minimum of 1 month post-surgery.

\section{Data collection}

Data on clinical presentation, biochemical, radiological and histological diagnosis, and surgical and pharmacological treatment were retrospectively collected from the patients' medical files in a standardized fashion. Post-surgery follow-up data, including blood pressure values, were collected until the end of December 2005. In patients whose most recent visit to our clinic took place before January 2005, information on the current health status, blood pressure, and antihypertensive treatment was updated by telephone interviews of the patients and their primary physicians.

\section{Definitions}

Hypersecretion of (nor)epinephrine was defined as elevation of plasma and/or urine levels of (nor)epinephrine and/or its metabolite (nor)metanephrine above the upper range of normal. Malignancy was defined as histological evidence of tumor cells at sites where chromaffin tissue is normally absent and/or by evidence of distant metastases documented by imaging studies (Linnoila et al. 1990). Recurrence was defined as the reappearance of the disease as documented at reintervention or by combined biochemical and imaging tests, after complete eradication of the tumor. Hypertension was defined as repeated office readings of systolic and/or diastolic blood pressure exceeding 140/90 $\mathrm{mmHg}$ and/or the use of antihypertensive medication.

\section{Data analysis and statistics}

Survival of patients who underwent successful resection of apparently benign PHEO was estimated using the Kaplan-Meier method and compared with the life expectancy of a Dutch reference population that was matched for age, sex, and period. Demographic data 
were obtained from Statistics Netherlands (Centraal Bureau voor de Statistiek). The analysis was also performed for a subgroup of patients with metastatic PHEO. Pre- and post-surgery blood pressure values were compared using paired sample $t$-test. Baseline characteristics were compared between patients with metastatic and non-metastatic PHEO, using unpaired $t$-test, Wilcoxon rank sum test, and Fisher exact test, when appropriate. Results are presented as mean \pm s.D. unless mentioned otherwise. Statistical analysis was performed using Statistical Package for the Social Sciences (for Windows 12.0; SPSS, Chicago, IL, USA).

\section{Results}

\section{Clinical presentation and diagnosis}

Signs and symptoms at presentation are summarized in Table 1. Symptoms occurred episodically in $82 \%$ (55out of the 67) of patients, with a frequency of at least daily in $42 \%$ (23 out of the 55). In two patients, an adrenal tumor was found incidentally during work up of colon carcinoma and chest pain respectively. Seventy-seven percent (54 out of the 70) of patients had hypertension. Apart from pre-surgical $\alpha$ - and $\beta$-blockade, $64 \%$ (43 out of the 67 ) were on antihypertensive drugs. Age at initial diagnosis of PHEO was $46.1 \pm 15.6$ (range 21-78) years. Hypersecretion of norepinephrine only occurred in $35 \%$ (20 out of the 57), epinephrine only in 7\% (4 out of the 57), and both epinephrine and norepinephrine in 58\% (33 out of the 57) of patients. PHEOs were located as follows: left adrenal $(n=22)$, right adrenal $(n=33)$, bilateral adrenal $(n=6)$, and extra-adrenal $(n=8: 5$ retroperitoneal, three in the bladder). Ninety-three percent (43 out of the 46) of tumors detected by anatomical imaging (CT, MRI, and ultrasound) were positive on ${ }^{123}$ I-MIBG scintigraphy. Histological findings in all

Table 1 Symptoms and signs at initial presentation

\begin{tabular}{llc}
\hline & \multicolumn{2}{c}{ Frequency $(n)$} \\
\cline { 2 - 3 } Symptoms and signs & Observed & Reported a \\
\hline Headache & $77 \%(40 / 52)$ & $60-90 \%$ \\
Palpitations & $72 \%(39 / 54)$ & $50-70 \%$ \\
Diaphoresis & $87 \%(47 / 54)$ & $55-75 \%$ \\
Pallor & $57 \%(27 / 47)$ & $40-45 \%$ \\
Nausea & $70 \%(35 / 50)$ & $20-40 \%$ \\
Flushing & $33 \%(14 / 43)$ & $10-20 \%$ \\
Tiredness & $68 \%(39 / 57)$ & $25-40 \%$ \\
Anxiety/panic attacks & $65 \%(24 / 37)$ & $20-40 \%$ \\
Weight loss & $44 \%(27 / 61)$ & $20-40 \%$ \\
Hypertension & $77 \%(54 / 70)$ & $50-60 \%$ \\
\hline
\end{tabular}

aLenders et al. 2005. tumors were consistent with PHEO. Fourteen patients had an underlying familial tumor syndrome: five neurofibromatosis, eight multiple endocrine neoplasia (MEN) type 2A, and one MEN type 2B.

\section{Follow-up}

Of the 69 patients, two died within 4 weeks after surgery (Table 2). In three patients, metastatic lesions were detected intra-operatively. The remaining 64 patients were included in the follow-up analysis. Follow-up of these patients was $11.0 \pm 7.4$ (median 9, range 1-38) years. In 20 patients, the most recent clinical visit took place more than one 1 year before the final analysis (median 5, range 1-7 years). Three patients were lost to follow-up at 2, 8, and 27 years after surgery.

Two patients experienced a benign recurrence (one with MEN 2B). In one patient, initial surgery was incomplete, and plasma catecholamines only normalized after resection of the rest tumor.

Seven additional patients developed metastases, within 1-14 years after the initial diagnosis (Table 3). There were no significant differences between patients with metastatic and non-metastatic PHEO with respect to sex, age at diagnosis, pre-surgical plasma catecholamine levels, and extra-adrenal tumor location (Table 4). All patients with metastases died. Survival since the diagnosis of metastases was $2.6 \pm 0.8$ (range 0-6) years. Twelve additional patients died during follow-up, all of whom were considered disease free although the cause of death is unknown in 5 out of these 12 patients (Table 3 ).

\section{Survival}

For the 64 patients who underwent successful surgery for non-metastatic PHEO, Kaplan-Meier estimates showed 5- and 10-year survival rates of $85.8 \%$ (95\% CI:

Table 2 Follow-up

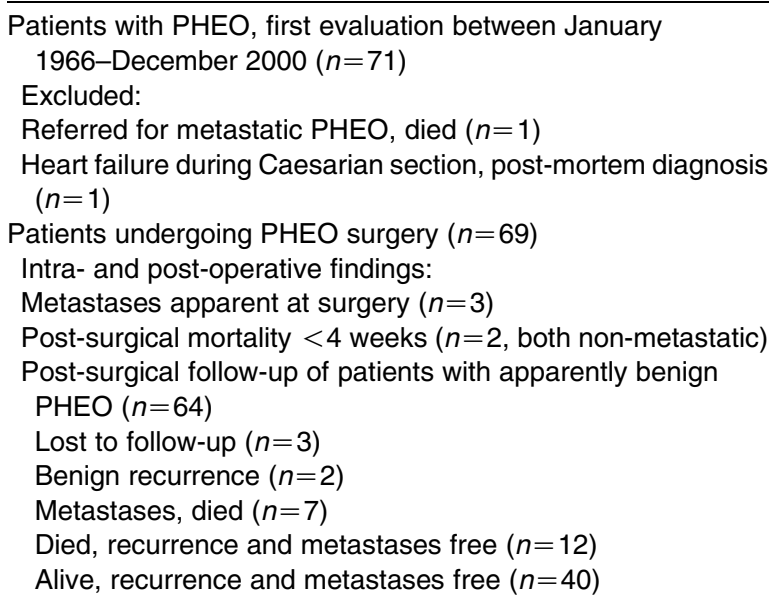


Table 3 Mortality

\begin{tabular}{|c|c|c|c|c|c|c|}
\hline $\begin{array}{l}\text { Sex/age at } \\
\text { diagnosis }\end{array}$ & $\begin{array}{l}\text { Year of } \\
\text { surgery }\end{array}$ & Syndrome & $\begin{array}{l}\text { Primary } \\
\text { tumor } \\
\text { location }\end{array}$ & $\begin{array}{l}\text { Metastases-free } \\
\text { survival }(y)\end{array}$ & $\begin{array}{c}\text { Post-surgery/ } \\
\text { metastases } \\
\text { survival }(y)\end{array}$ & Cause of death \\
\hline \multicolumn{7}{|c|}{ Non-metastatic PHEO } \\
\hline F50 & 1984 & - & $\mathrm{R}$ adrenal & - & 0 & Post-surgery sepsis \\
\hline M47 & 1977 & MEN2A & $\mathrm{L}$ adrenal & - & 0 & $\begin{array}{l}\text { Post-surgery pulmonary } \\
\text { embolism }\end{array}$ \\
\hline M54 & 1995 & MEN2A & $\mathrm{L}+\mathrm{R}$ adrenal & - & 1 & Car accident \\
\hline F63 & 1998 & - & $\mathrm{R}$ adrenal & - & 2 & Unknown \\
\hline F30 & 1988 & MEN2B & $\mathrm{L}+\mathrm{R}$ adrenal & - & 3 & Unknown \\
\hline F48 & 1966 & - & Extra-adrenal & - & 3 & Sub-arachnoid hemorrhage \\
\hline F52 & 1974 & NF & $\mathrm{L}$ adrenal & - & 4 & Unknown \\
\hline F62 & 1977 & - & $\mathrm{R}$ adrenal & - & 5 & Metastatic colon carcinoma \\
\hline F54 & 1990 & NF & $\mathrm{R}$ adrenal & - & 7 & Mesenteric sarcoma \\
\hline M73 & 1989 & MEN2A & $\mathrm{L}+\mathrm{R}$ adrenal & - & 10 & Gastric bleeding \\
\hline F60 & 1993 & - & $\mathrm{L}$ adrenal & - & 11 & Unknown \\
\hline M67 & 1987 & - & $\mathrm{R}$ adrenal & - & 13 & Cardiac \\
\hline F64 & 1972 & NF & $\mathrm{R}$ adrenal & - & 14 & Unknown \\
\hline $\mathrm{F} 51$ & 1972 & - & $\mathrm{L}$ adrenal & - & 21 & Myocardial infarction \\
\hline \multicolumn{7}{|c|}{ Metastatic PHEO } \\
\hline $\mathrm{F} 45$ & 1989 & - & $\mathrm{L}$ adrenal & 0 & $0 / 0$ & $\begin{array}{l}\text { Multi organ failure post- } \\
\text { PHEO surgery }\end{array}$ \\
\hline M46 & 1972 & - & $\mathrm{L}$ adrenal & 0 & $0 / 0$ & $\begin{array}{l}\text { Cachexia post-PHEO } \\
\text { surgery }\end{array}$ \\
\hline M78 & 1998 & - & $\mathrm{R}$ adrenal & 1 & $2 / 1$ & Suicide \\
\hline M66 & 1974 & - & $\mathrm{R}$ adrenal & 0 & $4 / 4$ & $\begin{array}{l}\text { Complication of metastatic } \\
\text { PHEO }\end{array}$ \\
\hline F32 & 1985 & - & $\mathrm{L}$ adrenal & 3 & $5 / 2$ & Ruptured aortic aneurysm \\
\hline F32 & 1988 & - & $\mathrm{L}$ adrenal & 3 & $6 / 3$ & Unknown \\
\hline M52 & 1974 & - & $\mathrm{R}$ adrenal & 0 & $6 / 0$ & Unknown \\
\hline M71 & 1992 & - & $\mathrm{L}$ adrenal & 7 & $10 / 3$ & $\begin{array}{l}\text { Pneumonia, metastatic } \\
\text { PHEO }\end{array}$ \\
\hline F30 & 1984 & - & Extra-adrenal & 5 & $10 / 5$ & $\begin{array}{l}\text { Septic shock post-bowel } \\
\text { surgery }\end{array}$ \\
\hline M75 & 1989 & - & $\mathrm{L}$ adrenal & 14 & $16 / 2$ & $\begin{array}{l}\text { Complication of abdominal } \\
\text { metastases }\end{array}$ \\
\hline
\end{tabular}

77.2-94.4\%) and $74.2 \%$ (95\% CI: $62.0-86.4 \%$ ) versus 95.5 and $89.4 \%$ in the reference population respectively $(P<0.05$, Fig. 1). The post-surgical survival of a subgroup of patients who (eventually) developed metastatic PHEO was well below that of a matched reference population (Fig. 2). The survival of patients with really benign PHEO (no metastases during followup) was not significantly different from the reference population (Fig. 3): 5- and 10-year survival rates $89.3 \%$ (95\% CI: 81.3-97.4\%) and 84.1\% (95\% CI: 73.6-94.5\%) versus 96.2 and $90.9 \%$ in the reference population (ns).

\section{Blood pressure and catecholamines}

In patients with a post-surgical follow-up of at least 1 year, 67\% (35 out of the 62) were hypertensive. Of 47 patients with hypertension prior to surgery, 17 (36\%) became and remained normotensive. Of the 30 recurrence-free patients with hypertension both before surgery and at most recent post-surgical follow-up, mean blood pressure had decreased from $164 \pm 28 / 95 \pm 12$ to $143 \pm 21 / 87 \pm 11 \mathrm{mmHg}(P<0.001$ for systolic and diastolic blood pressure).

Plasma catecholamine levels normalized after surgery, except in three patients with slightly elevated levels, despite lack of recurrence on imaging studies.

\section{Discussion}

The main finding of our study is that patients undergoing successful surgery for apparently benign PHEO have a reduced life expectancy when compared with a sex, age, and period-matched reference population. This can be ascribed fully to the patients who developed metastatic disease while survival was not reduced in the really benign patients. We also show that only one-third of recurrence-free patients become and remain normotensive on the long-term following surgery. 
Table 4 Benign versus malignant PHEO

\begin{tabular}{lcc}
\hline & Benign PHEO & $\begin{array}{c}\text { Malignant } \\
\text { PHEO }\end{array}$ \\
\hline$N$ & 59 & 10 \\
Sex $(\mathrm{M} / \mathrm{F})$ & $19 / 40$ & $6 / 4$ \\
Age at diagnosis $(\mathrm{y})$ & $45.2 \pm 15.3$ & $51.1 \pm 16.3$ \\
Pre-surgery E/(E+NE) ratio & $0.21 \pm 0.22$ & $0.14 \pm 0.24$ \\
& $(n=43)$ & $(n=10)$ \\
Extra-adrenal tumor & $12 \%(7 / 59)$ & $10 \%(1 / 10)$ \\
\hline
\end{tabular}

Benign: no metastatic lesions during follow-up. Malignant: metastatic lesions during follow-up. M, male; $F$, female; $E$, epinephrine; NE, norepinephrine.

Only a limited number of publications of the past 10 years provided long-term follow-up data on morbidity and mortality after PHEO surgery (Plouin et al. 1997, Goldstein et al. 1999, Amar et al. 2005, KhorramManesh et al. 2005). Differences in study population, length of follow-up, definitions of recurrent and malignant disease, and analysis methods hamper comparison of theses studies. The rates of benign recurrence after successful surgery of non-metastatic PHEO ranged from 3.3 to $6.1 \%$ (Plouin et al. 1997, Amar et al. 2005, Khorram-Manesh et al. 2005), versus $3 \%$ in the present study. The prevalence of malignant disease, ranged from 6.6 to $16 \%$ (Plouin et al. 1997, Goldstein et al. 1999, Amar et al. 2005; KhorramManesh et al. 2005), versus $14 \%$ in the present study. Our observation of a 5-year metastases-free survival of $88 \%$ after successful surgery for really benign PHEO is

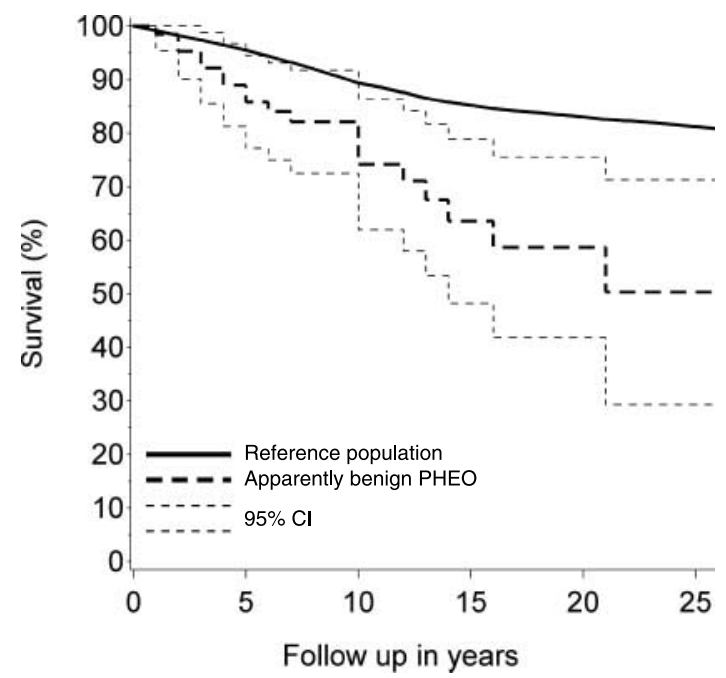

Figure 1 Kaplan-Meier curve of survival after pheochromocytoma surgery of 64 patients with apparently benign disease compared with the Kaplan-Meier survival curve of a matched reference population.

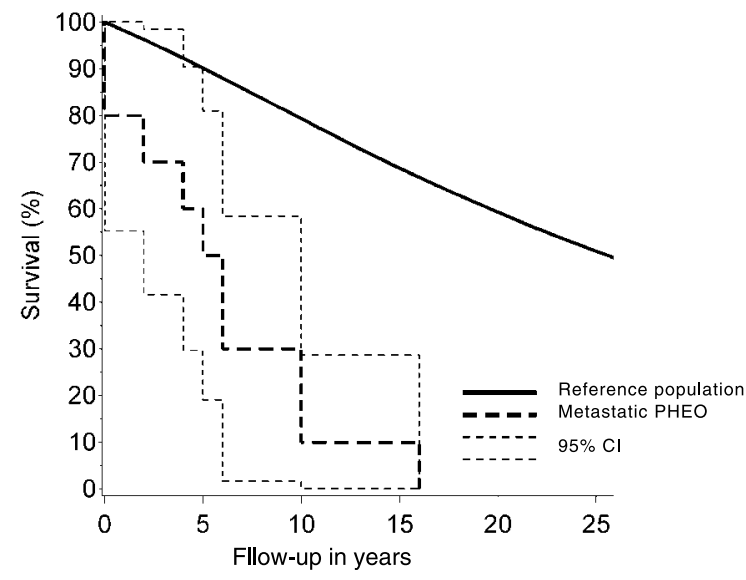

Figure 2 Kaplan-Meier curve of survival after pheochromocytoma surgery of ten patients (eventually) diagnosed with metastatic disease compared with the Kaplan-Meier survival curve of a matched reference population.

comparable with that of $92-94 \%$ found in these studies (Plouin et al. 1997, Amar et al. 2005).

Since there are no established pathology criteria to distinguish benign from malignant PHEO, clinical, biochemical, and temporal characteristics have been evaluated as surrogate predictors of malignant recurrence. Features that were implied to be associated with shorter PHEO-free survival after surgery include extraadrenal tumor location, low epinephrine/epinephrine + norepinephrine ratio (Plouin et al. 1997, Amar et al. 2005,

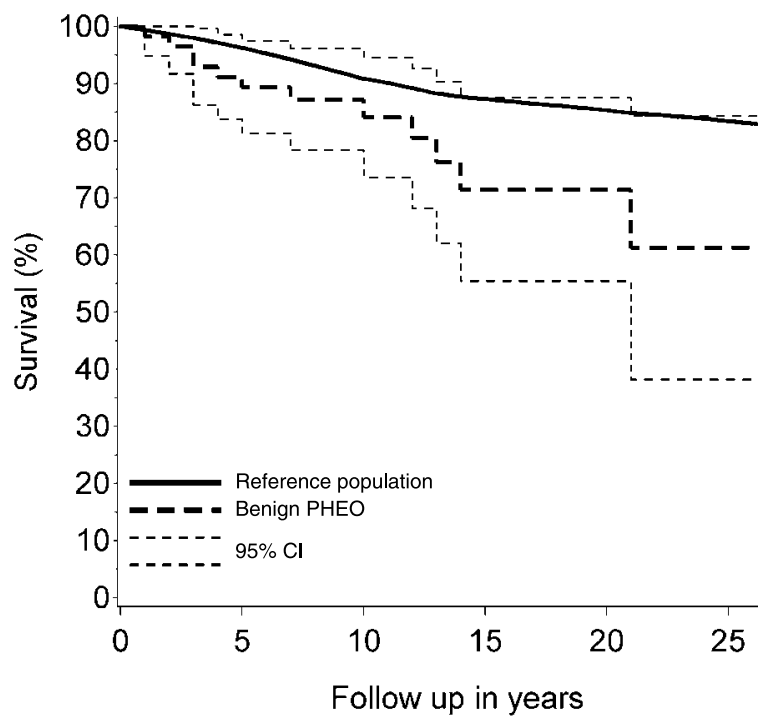

Figure 3 Kaplan-Meier curve of survival after pheochromocytoma surgery of 57 patients with benign disease compared with the Kaplan-Meier survival curve of a matched reference population. 
Khorram-Manesh et al. 2005, Plouin \& Gimenez-Roqueplo 2006) and familial disease, especially SDHBrelated PHEO (Neumann et al. 2004, Benn et al. 2006). In the present study, no predictors of malignant recurrence were identified. However, the lack of significant differences between patients with benign and malignant PHEO may be related to a limited sample size.

Survival after uncomplicated PHEO surgery was lower than in a Dutch reference population. In two previous studies, the survival after PHEO surgery was compared with the expected life expectancy of a general reference population (Stenstrom et al. 1988, Khorram-Manesh et al. 2005). In a Swedish cohort of 121 patients, 42 patients died during the observation period versus 23.1 expected deaths in the control population $(P<0.001$; Khorram-Manesh et al. 2005). In a prior study performed at the same centre, however, the observed and expected mortality were similar (Stenstrom et al. 1988). Our study confirms that patients with successfully resected PHEO still have a reduced life expectancy. This excess mortality is explained by the development of fatal metastatic disease in $11 \%$ of patients. In patients with benign PHEO, longstanding hypertension and catecholamine excess prior to surgery can induce (partially) irreversible structural vascular changes (Plouin et al. 1997, Khorram-Manesh et al. 2005), which might result in increased cardiovascular mortality. The latter was not confirmed by our study, although our study sample does not allow for a comparison of cardiovascular morbidity to that of the general population.

Our findings reinstate that despite radical surgery, a substantial portion of recurrence-free patients remains hypertensive. Although this refutes the original notion, that PHEO is a surgically curable cause of hypertension, blood pressure values of patients with persistent hypertension were significantly lower post- than presurgery. Two-thirds of patients with hypertension at presentation were also hypertensive at most recent follow. In previous studies, this frequency ranged from 38-71\% (Pruszczyk et al. 1991, Plouin et al. 1997, Khorram-Manesh et al. 2005). Age, familial hypertension, and the presence of hypertension at 1 year after surgery were identified as predictors of hypertension on the long term (Plouin et al. 1997). This persistence of hypertension is probably due to structural and functional vascular abnormalities that may be induced by the longstanding antecedent hypertension.

There are two issues that have to be kept in mind when interpreting the Nijmegen cohort. The most important of these is that outcome has been shown to be better in PHEO patients that were diagnosed more recently than in those diagnosed (many) years earlier. This is attributed to the improvement of diagnostic, surgical (laparoscopic surgery has replaced open resection), and anesthetic techniques (Amar et al. 2005, Plouin \& GimenezRoqueplo 2006). All our patients were operated before 2001, mainly through open procedures. Secondly, the prognosis of patients with PHEO is largely determined by the underlying genotype. Genetic testing was not systematically performed in all patients, partly due to the fact that comprehensive genetic testing, including SDHB mutations, became available after 2001. The observed prevalence of disease-causing mutations of $20 \%$ might, in fact, be an underestimation, and the results may theoretically be influenced by the portion of unrevealed mutations.

In conclusion, patients who undergo successful surgery for apparently benign PHEO have a reduced life expectancy when compared with the general population. The excess mortality is explained by the development of metastatic disease during post-surgical follow-up in some of the patients. By contrast, the survival of patients who do not develop metastatic disease is not different from that of the general population. Hypertension persists in two-thirds of recurrence-free patients. Lifelong follow-up of patients who had surgery for PHEO is warranted.

\section{Declaration of interest}

The authors declare that there is no conflict of interest that could be perceived as prejudicing the impartiality of the research reported.

\section{Funding}

This research did not receive any specific grant from any funding agency inthe public, commercial or not-for-profit sector.

\section{Acknowledgements}

The authors regret to announce that AAJ Verhofstad is now deceased.

\section{References}

Amar L, Servais A, Gimenez-Roqueplo AP, Zinzindohoue F, Chatellier G \& Plouin PF 2005 Year of diagnosis, features at presentation, and risk of recurrence in patients with pheochromocytoma or secreting paraganglioma. Journal of Clinical Endocrinology and Metabolism 90 2110-2116.

Benn DE, Gimenez-Roqueplo AP, Reilly JR, Bertherat J, Burgess J, Byth K, Croxson M, Dahia PL, Elston M, Gimm O et al. 2006 Clinical presentation and penetrance of pheochromocytoma/paraganglioma syndromes. Journal of Clinical Endocrinology and Metabolism 91 827-836. 
DeLellis RA, Lloyd RV, Heitz PU \& Eng C 2004 Pathology and Genetics: Tumours of Endocrine Organs. Oxford, UK: Oxford University Press.

Goldstein RE, O’Neill JA Jr, Holcomb GW, Morgan WM III, Neblett WW III, Oates JA, Brown N, Nadeau J, Smith B, Page DL et al. 1999 Clinical experience over 48 years with pheochromocytoma. Annals of Surgery 229 755-764.

van Heerden JA, Roland CF, Carney JA, Sheps SG \& Grant CS 1990 Long-term evaluation following resection of apparently benign pheochromocytoma(s)/paraganglioma(s). World Journal of Surgery 14 325-329.

van der Horst-Schrivers AN, Kerstens MN \& Wolffenbuttel BH 2006 Preoperative pharmacological management of phaeochromocytoma. Netherlands Journal of Medicine 64 290-295.

Ilias I, Shulkin B \& Pacak K 2005 New functional imaging modalities for chromaffin tumors, neuroblastomas and ganglioneuromas. Trends in Endocrinology and Metabolism 16 66-72.

Khorram-Manesh A, Ahlman H, Nilsson O, Friberg P, Oden A, Stenstrom G, Hansson G, Stenquist O, Wangberg B, Tisell LE et al. 2005 Long-term outcome of a large series of patients surgically treated for pheochromocytoma. Journal of Internal Medicine 258 55-66.

Lenders JW, Pacak K, Walther MM, Linehan WM, Mannelli M, Friberg P, Keiser HR, Goldstein DS \& Eisenhofer G 2002 Biochemical diagnosis of pheochromocytoma: which test is best? Journal of the American Medical Association 287 1427-1434.

Lenders JW, Eisenhofer G, Mannelli M \& Pacak K 2005 Phaeochromocytoma. Lancet 366 665-675.

Linnoila RI, Keiser HR, Steinberg SM \& Lack EE 1990 Histopathology of benign versus malignant sympathoadrenal paragangliomas: clinicopathologic study of 120 cases including unusual histologic features. Human Pathology 21 1168-1180.

Modlin IM, Farndon JR, Shepherd A, Johnston ID, Kennedy TL, Montgomery DA \& Welbourn RB 1979 Phaeochromocytomas in 72 patients: clinical and diagnostic features, treatment and long term results. British Journal of Surgery 66 456-465.
Neumann HP, Pawlu C, Peczkowska M, Bausch B, McWhinney SR, Muresan M, Buchta M, Franke G, Klisch J, Bley TA et al. 2004 Distinct clinical features of paraganglioma syndromes associated with SDHB and SDHD gene mutations. Journal of the American Medical Association 292 943-951.

Pacak K, Keiser H \& Eisenhofer G 2005 Pheochromocytoma. In Textbook of Endocrinology, pp 2501-2534. Eds LJ De Groot \& JL Jameson. 5 Philadelphia, PA: Elsevier Saunders, Inc.

Plouin PF \& Gimenez-Roqueplo AP 2006 Initial work-up and long-term follow-up in patients with phaeochromocytomas and paragangliomas. Best Practice and Research. Clinical Endocrinology and Metabolism 20 421-434.

Plouin PF, Chatellier G, Fofol I \& Corvol P 1997 Tumor recurrence and hypertension persistence after successful pheochromocytoma operation. Hypertension 29 1133-1139.

Pruszczyk P, Januszewicz W, Feltynowski T, Chodakowska J, Wocial B, Pachocki R, Nielubowicz J \& Szostek M 1991 Long term follow-up after surgical removal of pheochromocytoma - observations in 61 patients. Clinical and Experimental Hypertension 13 1179-1194.

Scott HW Jr \& Halter SA 1984 Oncologic aspects of pheochromocytoma: the importance of follow-up. Surgery 96 1061-1066.

Stenstrom G, Ernest I \& Tisell LE 1988 Long-term results in 64 patients operated upon for pheochromocytoma. Acta Medica Scandinavica 223 345-352.

Willemsen JJ, Ross HA, Jacobs MC, Lenders JW, Thien T, Swinkels LM \& Benraad TJ 1995 Highly sensitive and specific HPLC with fluorometric detection for determination of plasma epinephrine and norepinephrine applied to kinetic studies in humans. Clinical Chemistry 41 1455-1460.

Willemsen JJ, Sweep CG, Lenders JW \& Ross HA 2003 Stability of plasma free metanephrines during collection and storage as assessed by an optimized HPLC method with electrochemical detection. Clinical Chemistry 49 1951-1953. 